\title{
Failure Response of Simultaneously Pre-Stressed and Laser Irradiated Aluminum Alloys
}

\author{
Mohsan Jelani ${ }^{1}$, Zewen $\mathrm{Li}^{2, *}$, Zhonghua Shen ${ }^{1,2}$ and Maryam Sardar ${ }^{1}$ \\ 1 School of Science, Nanjing University of Science and Technology, Nanjing 210094, China; \\ jelani373@gmail.com (M.J); shenzh@njust.edu.cn (Z.S); maryam.ac.cn@gmail.com (M.S) \\ 2 Advanced Launching Co-innovation Centre, Nanjing University of Science and Technology, \\ Nanjing 210094, China \\ * Correspondence: lizewen@njust.edu.cn; Tel.: +86-025-8431-5687
}

Academic Editor: Cem Selcuk

Received: 22 February 2017; Accepted: 25 April 2017; Published: 29 April 2017

\begin{abstract}
The failure response of aluminum alloys (Al-6061 and Al-7075) under the condition of simultaneously pre-stressing and laser heating was investigated. Specimens were subjected to predetermined preloading states and then irradiated by continuous wave fiber $(\mathrm{Yb})$ laser. For all specimens, it was found that the yield stress decreased with increasing laser power density. This implies that the load-bearing capacity of the specimens reduced under increased thermal or tensile loading. Consequently, the specimen's failure time was shortened by increasing either laser power density or preloaded speed. For Al-6061, a remarkable reduction in failure time by the increase of laser power density is found. However, for Al-7075, under higher preloaded speeds, comparatively smaller impact of laser power density on the failure time is reported. Moreover, for Al-6061, relatively a more non-uniform variation in the average failure time with the increase of laser power density or preloaded speed is observed. The failure mode of Al-6061 turned from brittle to ductile at higher laser power densities; whereas for Al-7075, it changed from quasi-brittle to ductile. At higher preloaded speeds, a greater degree of melting and ablation phenomenon can be seen due to relatively higher temperatures and higher heating rates.
\end{abstract}

Keywords: Al-alloys; CW laser; tensile loading; structural failure

\section{Introduction}

The development of a general understanding for durability and damage analysis for structural components exposed to severe thermal heating is the most desirable knowledge in the defense and aerospace industry. In a broad range of load-bearing applications, for instance aircraft structures, lightweight structures, bridge decks, marine crafts and off-shore platforms, structural components may be subjected to severe thermal loading. The possible sources for the intense heating environment to preloaded components may be the aerodynamic heating, laser irradiation or localized intense fire [1,2]. For example, when the work piece is clamped or the aircraft and missiles are flying at high speed, the specimen will be in the condition of external loading. In crash circumstances, automotive parts will face the load conditions where both high strain rate and rising temperature by adiabatic heating can be induced [3]. Structural reliability will be affected by the presence of thermal stresses, as well as the degradation of the strength properties at elevated temperatures caused by the heating. Since the modulus and yield stress of material generally decreases with the increase of temperature, material strength degrades under elevated temperature situations [4]. In general, dynamic failure processes are strongly influenced by the state of stress, the strain rate and loading history. The preloading or strain rate and temperature affect the material flow response significantly in deformation processes. Being subjected to quasi-static loading, strain hardening induces an enhancement in the force needed for the 
deformation process, which may act as a stabilizing effect. In the case of dynamic loading, additional effects on the deformation process, for example on flow stress and the ductility of the material, may be experienced $[5,6]$.

The understanding of thermo-mechanical behavior in a severe environment is essential to develop component design, product resistance to shock loading, for crashworthiness, safety and reliability in service performance assessment. There has been considerable work on understanding how structural metals deform under transient tensile conditions [7-9]. However, the research about the laser damage effect of aluminum and other structural materials under preloaded conditions is infrequent. Considering the combined effect of mechanical load and laser irradiation, a brief review of studies on aluminum alloys and other structural materials is presented here. Florando et al. [10] investigated the effect of laser irradiation on the failure response of aluminum alloy (Al-7075) by using 3D digital image correlation and a series of thermocouples. The specimens were held under constant load and then irradiated by a diode laser $(780 \mathrm{~nm}, 5 \mathrm{~kW})$. The results exhibited non-uniform temperature and strain field distributions; moreover, the strain rate increased rapidly as the sample approached the failure point. The strength and failure response was also modeled and compared with experiments. Medford et al. [11] presented an analytical model to find the failure threshold and to predict the thermal and structural behavior of aluminum alloys subjected to combined effects of laser exposure and mechanical loading. They employed a continuous wave $(\mathrm{CW}) \mathrm{CO}_{2}$ laser for irradiation under tensile or compression loading in the presence of tangential subsonic flow. It was observed that the combined laser exposure and mechanical loading considerably reduced the damaging threshold energy and room temperature tensile strength. Long et al. [12] had presented relationships between different parameters, such as laser power density, preload and the thickness on the failure time of the carbon fiber/epoxy composite laminates subjected to $\mathrm{CW} \mathrm{CO}_{2}$ laser. Yang et al. [13] investigated the $\mathrm{CW}$ laser damage effect on a steel structure under preloaded invariable stretching stress. They attempted to develop the empirical relationships between the stretching stress and rupture temperature. On the basis of the experimental results, an empirical formula was derived, which relates the stretching stress and rupture temperature.

The present study experimentally examined the failure behavior of aluminum alloys exposed to combined tensile loading and laser irradiation. The purpose of the laser damaging was to explore the influence of laser power density on the strength degradation and failure time (the time from the start of laser irradiation to the failure of the specimen) of the preloaded specimens. Additionally, it was aimed to explore and provide a comparative behavior of two different kinds of aluminum alloys under simultaneous tensile loading and laser heating. To accomplish these objectives, Al-6061 and Al-7075 aluminum alloys were subjected to simultaneous tensile loading and CW ytterbium fiber laser irradiations. The deformation behavior and failure time were recorded by the tensile testing setup and a high speed video camera, respectively.

\section{Materials and Methods}

The tested materials were purchased from ASM Aerospace Specification Metals Inc. (Pompano Beach, FL, USA). The materials' chemical composition and main properties provided by the supplier are reported in Tables 1 and 2, respectively.

The Al-based alloys under test are 6061-T6 and 7075-T6, where T6 means that the alloy is heat treated and artificially aged. Aluminum alloy 6061-T6 (Al-6061) is one of the most extensively used of the 6000 series aluminum alloys. It is a versatile heat-treatable extruded alloy with medium to high strength capabilities and excellent corrosion resistance. It is largely used in aircraft and aerospace components, transport and structural applications [14]. The chemical composition of the Al-6061 is given in Table 1. The major alloying elements are magnesium and silicon.

Aluminum alloy 7075-T6 (Al-7075) is a high-strength alloy with strong corrosion resistance. It is widely used in the aircraft and aerospace industries for highly-stressed structural parts [15]. 
The chemical composition of the Al-7075 is also given in Table 1. The major alloying elements are zinc and magnesium.

Table 1. Chemical composition of $\mathrm{Al}$ alloys in weight \% [16,17]. (Bal: Balance)

\begin{tabular}{cccccccccccc}
\hline Alloy & $\mathbf{S i}$ & $\mathbf{F e}$ & $\mathbf{C u}$ & $\mathbf{M n}$ & $\mathbf{M g}$ & $\mathbf{Z n}$ & $\mathbf{T i}$ & $\mathbf{C r}$ & $\mathbf{N i}$ & $\mathbf{P b}$ & $\mathbf{A l}$ \\
\hline Al-6061 & 0.62 & 0.46 & 0.29 & 0.09 & 0.88 & 0.04 & 0.05 & 0.17 & 0.01 & & Bal. \\
Al-7075 & 0.09 & 0.22 & 1.52 & 0.12 & 2.42 & 5.72 & 0.06 & 0.19 & & 0.02 & Bal. \\
\hline
\end{tabular}

For the experiments, rectangular strip-shaped specimens with dimensions of $150 \times 10 \times 2 \mathrm{~mm}^{3}$ were used. The specimen dimensions were chosen in accordance with ASTM-B557 specifications and from available literature $[16,18,19]$. The physical and mechanical properties of the investigated alloys are reported in the Table 2.

Table 2. Mechanical and physical properties of the aluminum alloys [20-22].

\begin{tabular}{ccc}
\hline Physical Properties & Al-6061 & Al-7075 \\
\hline Room temperature tensile strength $(\mathrm{MPa})$ & 403 & 605 \\
Room temperature yield strength $(\mathrm{MPa})$ & 370 & 565 \\
Density $\left(\mathrm{g} \mathrm{cm}^{-3}\right)$ & 2.7 & 2.8 \\
Melting point $\left({ }^{\circ} \mathrm{C}\right)$ & $582-652$ & $477-635$ \\
Thermal conductivity $\left(\mathrm{Wm}^{-1} \mathrm{~K}^{-1}\right)$ & 173 & 130 \\
Thermal diffusivity $\left(\mathrm{mm}^{2} \mathrm{~s}^{-1}\right)$ & 70 & 46 \\
\hline
\end{tabular}

Before performing the experiments, the room temperature ultimate tensile strengths of both types of specimens were measured by using the JVJ-50S universal tensile testing machine (SIOMM, Shanghai, China). The resulting average values of room temperature yield strength and ultimate tensile strengths for Al-6061 and Al-7075 alloys are given in Table 2. Experiments were performed for $85 \%$ of ultimate tensile strength in each case, but with varying preloaded speeds of $0.5,1,2$ and $4 \mathrm{~mm} / \mathrm{min}$, respectively. The specified preload was provided on the specimen by the JVJ-50S universal testing machine by pre-setting the loading speed. Tensile loading experiments were designed in accordance with the ASTM-B557 standards, while the preloaded speeds were obtained from the literature [19]. After reaching $85 \%$ of ultimate tensile strength, the specimens were kept under a constant loading state. The predetermined constant preload values were $6.85 \mathrm{kN}$ (340 MPa) and $12.1 \mathrm{kN}$ (514 MPa) for Al-6061 and Al-7075, respectively. The loading profile was chosen to examine the effect of loads on the observed behavior. However, in the following results of Figures 1 and 2, the first loading part (before reaching the determined preload) of the curves was cut, and corresponding curves only represent the specimens after reaching the constant preloaded state. In Table 3, the test conditions of laser power densities and loading speeds are given.

Table 3. Experimental parameters: laser power densities and loading speeds.

\begin{tabular}{ccccc}
\hline Laser Power Density $\left(\mathrm{kW} / \mathrm{cm}^{2}\right)$ & $\mathbf{1 . 1}$ & $\mathbf{1 . 6}$ & $\mathbf{2 . 2}$ & $\mathbf{2 . 7}$ \\
\hline Loading speed $(\mathrm{mm} / \mathrm{min})$ & 0.5 & 1 & 2 & 4 \\
\hline
\end{tabular}

The laser began to irradiate the specimens while they were being held under a constant prescribed loading state. The distance between the laser emitter and the specimen was $60 \mathrm{~cm}$. The laser spot with a 7-mm diameter was perpendicularly focused on the center of the specimen, with four laser power densities of 1.1, 1.6, 2.2 and $2.7 \mathrm{~kW} / \mathrm{cm}^{2}$ respectively employed in the test. The $\mathrm{CW}$ ytterbium $(\mathrm{Yb})$ fiber laser (RFL-C1000, Raycus, Wuhan, Hubei, China) with a 1080-nm wavelength and $1 \mathrm{~kW}$ maximum power was used for laser irradiation. The specimens were continuously irradiated until 
failure occurred, and the exposure time required for complete failure was recorded by using high speed video camera. After the experiments, the fractured surfaces were examined by optical microscope. To get more reliable results, the experiments were repeated three times for each condition. However, no considerable difference in the results of multiple trials was found.

\section{Results and Discussion}

For the work presented in this paper, only one variable is held constant, that of the load on the test specimen. The temperature (via laser heating) of the specimen is increased until tensile failure occurred. The deformation of the specimen develops from thermoelastic effects including thermal expansion and modulus change through yielding to plastic deformation at high strain rates near failure. When the specimen is irradiated by the strong laser beam, the temperature in the laser-irradiated region rises quickly, and the thermal, as well as the mechanical properties of the specimens changed dramatically. These changes lead to the specimen's softening, melting and gasification spray. The thermal effects increased as the laser power density increased. For instance, the increased absorbed laser energy can enhance the temperature rise, heating rate and can lead to relatively rapid breakdown of specimens instead of melting or plastic deformation. The mechanism behind this deformation is that the ultimate strength of the specimen significantly decreases with the increase of the exposure loading or temperature. In other words, it can be said that the load-bearing capacity of the material will be reduced under increased thermal or tensile loading [12,23]. The laser irradiated area gets into the plastic yield stage, and with the increase of the exposure power density/time, the yield region expands to the specimen interior gradually and causes structural damage to the specimen [24].

\subsection{Failure Behavior}

Figure 1a-d demonstrates the failure behavior as a function of laser power density under fixed preloading speed for the Al-6061 type specimens. In Figure 1a, under the lowest laser power density of the $1.1 \mathrm{~kW} / \mathrm{cm}^{2}$ condition, the specimen's yield strength drops smoothly up to complete structural failure. This is because that combination of very low loading speed and low laser power density induced the very small temperature rise even less then the melting point, so concerning the specimen's deformation, and the softening process was relatively slow; while for higher laser power densities (Curves 2-4), the fractured process was shortened with the sharp drop in the specimen's yield strengths with the increase of irradiated laser power densities. As the laser power density increased, the specimen's temperature rose, which boosted the thermal activation process by accelerating the structural defects, annihilating the dislocations and enhancing the softening mechanism. Since the Al-6061 alloy is precipitation hardened and its primary strengthening development is through precipitate growth under controlled heating (aging) to a required state, combined (laser and tensile) loading and elevated temperature induced further precipitate growth (over aging) and strength reduction with the increase of laser power density [25]. In Figure 1b, for the lower laser power densities of 1.1 and $1.6 \mathrm{~kW} / \mathrm{cm}^{2}$, the specimens followed the same failure pattern with a slight difference in failure time, and both curves overlapped each other. The similarity in the deformation behavior might be attributed to limited thermal activated (movement of structural defects, etc.) processes up to specific absorbed energy level for the employed preloaded speed $(1 \mathrm{~mm} / \mathrm{min})$. Since it has been observed that in some situations the plastic deformation can be halted when the specimen is heated through certain temperature ranges [26], the overlapping of the latter part of the curves represents the delayed time in the specimens' failure instead of sudden fracture. However, the specimens fractured more rapidly with the further increase in laser power density to 2.2 and $2.7 \mathrm{~kW} / \mathrm{cm}^{2}$, respectively. In Figure 1c,d under the preloading speeds of $2 \mathrm{~mm} / \mathrm{min}$ and $4 \mathrm{~mm} / \mathrm{min}$ respectively, for the lowest laser power density of $1.1 \mathrm{~kW} / \mathrm{cm}^{2}$, the specimens took a comparatively long time to reach the yield strength and complete failure. Moreover, Curve 1 in Figure $1 \mathrm{c}$ and Curves 1 and 2 in Figure 1d showed comparatively different behavior. A more delayed decrease of stress over a considerable range of plastic deformation caused by the adiabatic character of the deformation process at a certain temperature range is observed. 
After reaching a specific temperature, the load sustained by the specimen started to drop, and fracture occurred shortly. The reason behind the initially slow strength degradation is the less sensitivity to modest temperature increases of strengthening precipitates in Al-6061 specimens, until a temperature where precipitates start to lose coherency [10]. When the preload continues to add strain energy to the continually-heated specimen with limited possibilities for dislocation movement, it eventually becomes energetically favorable to ease the load by fracturing. For the higher laser power densities, the specimen's failure occurred in a similar pattern, and relatively fast reduction of the stress can be seen for all of the preloaded speeds.
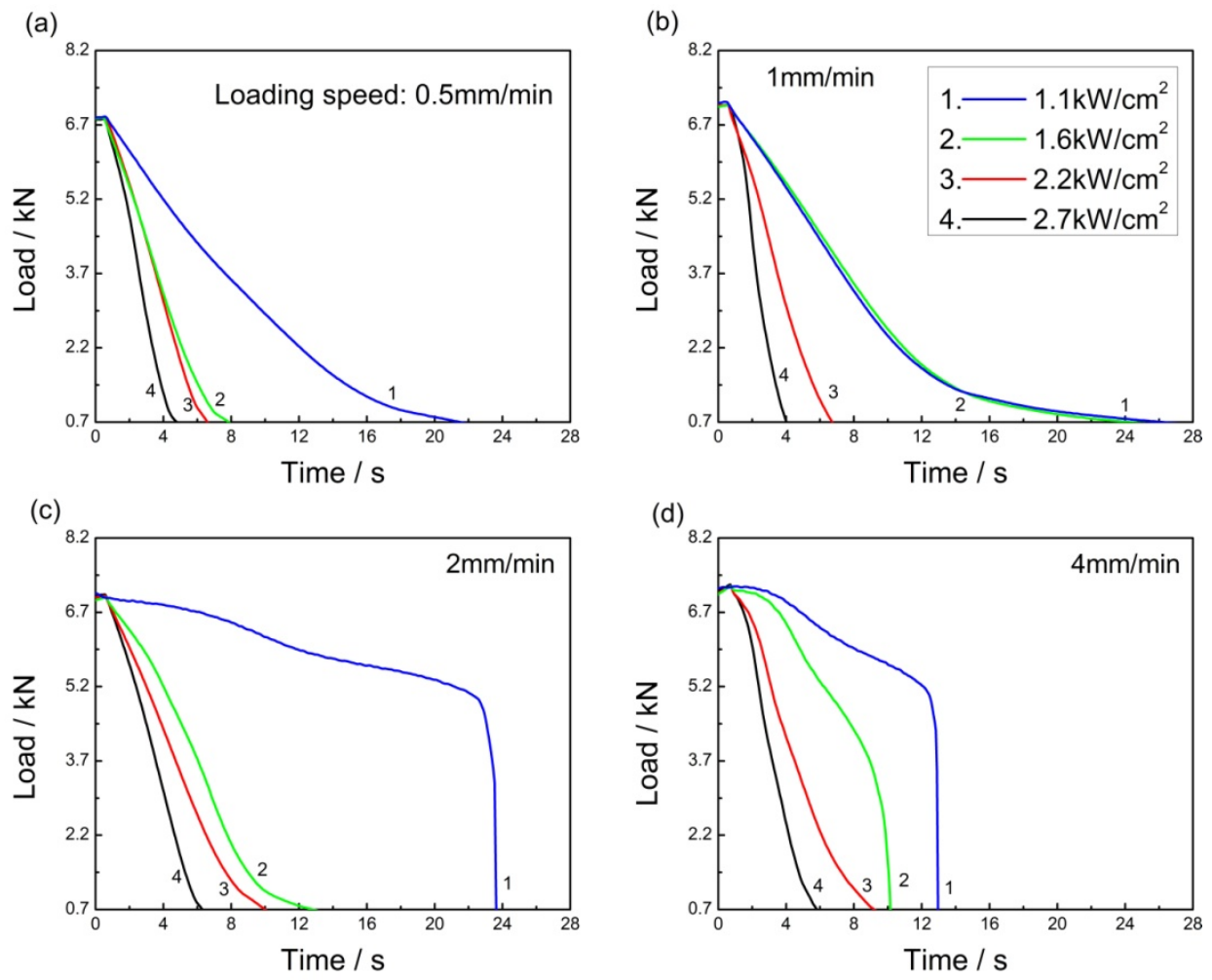

Figure 1. Failure behavior of Al-6061 specimens for various laser power densities under the fixed preloading speeds. (a) $0.5 \mathrm{~mm} / \mathrm{min}$; (b) $1 \mathrm{~mm} / \mathrm{min}$; (c) $2 \mathrm{~mm} / \mathrm{min}$; (d) $4 \mathrm{~mm} / \mathrm{min}$.

Figure 2a-d exhibits the failure behavior as a function of preloaded speeds under varying laser power density for the Al-7075 type specimens. In Figure 2a-d, under the lowest laser power density of $1.1 \mathrm{~kW} / \mathrm{cm}^{2}$, the specimen's yield strength drops smoothly and at the end slowed up before complete failure. From this, it can be concluded that loading speed could not produce any affect in mobilizing the thermo-mechanical properties with such low laser power density. Since Al-7075 material has relatively high mechanical properties, but low thermal conductivity and diffusivity values, the combination of low laser power density $\left(1.1 \mathrm{~kW} / \mathrm{cm}^{2}\right)$ and various loading speeds did not cause any noticeable change except softening and re-crystallization during the fracture process; while for higher laser power densities (Curves 2-4) in Figure 2a-d, the fractured process was shortened with a sharp drop in the specimen's yield strength with the increase of irradiated laser power densities. Again, as for Al-6061, Al-7075 has a similar strengthening mechanism, but different micro-structural states, so the same explanation for the rapid drop in stress along increasing laser power density is applicable. Fractured and yielding processes are thermally-activated and stress-driven movement, and this movement effectively depends on the strain rate (in our case, loading speed) and temperature. In the thermally-activated processes, an energy barrier should be removed for the movement development. 
The preloaded stress with various speeds acts to reduce the barrier when it is in the direction of movement and to elevate it when it opposes the movement.
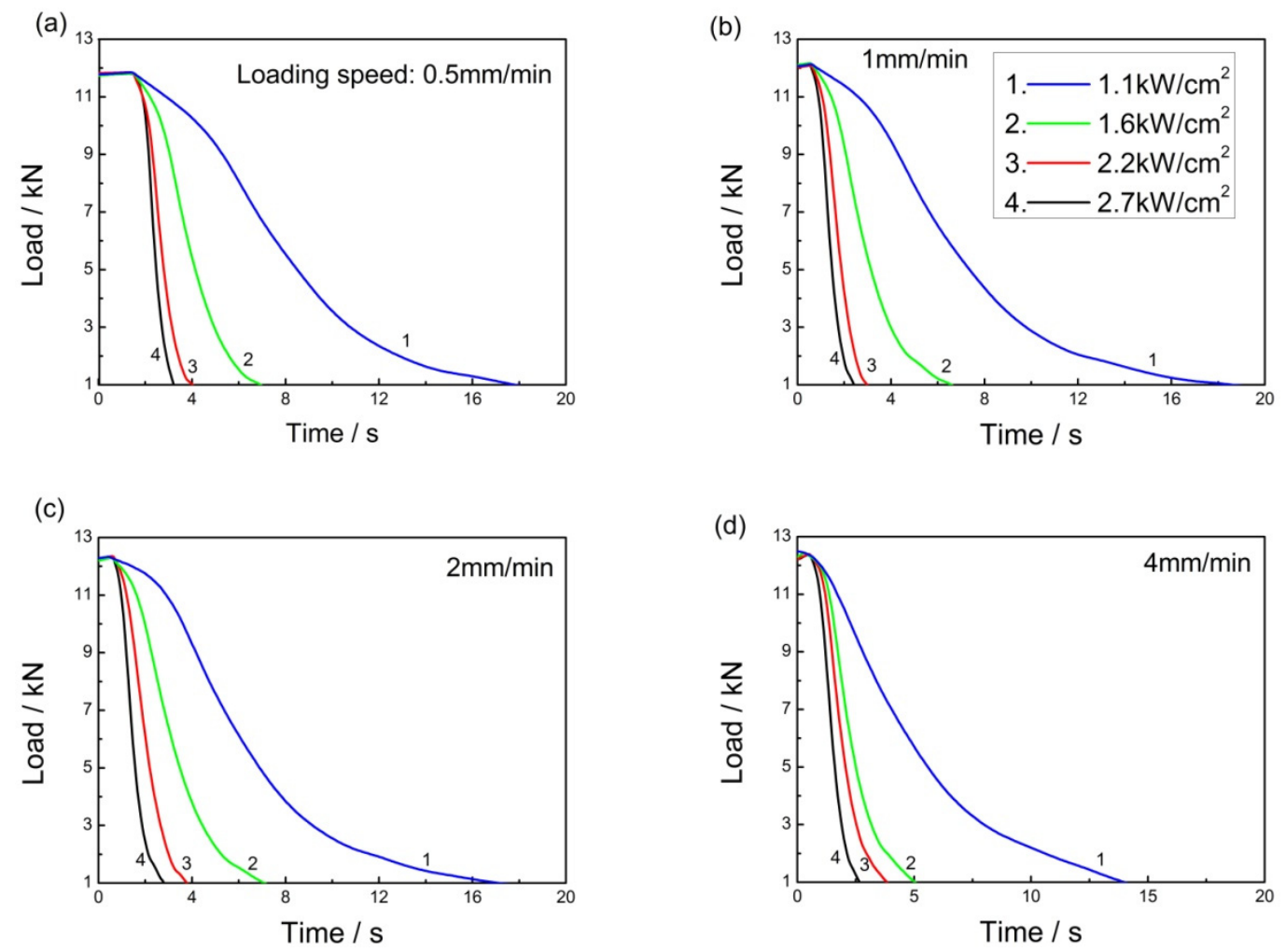

Figure 2. Failure behavior of Al-7075 specimens for various laser power densities under the fixed preloading speeds. (a) $0.5 \mathrm{~mm} / \mathrm{min}$; (b) $1 \mathrm{~mm} / \mathrm{min}$; (c) $2 \mathrm{~mm} / \mathrm{min}$; (d) $4 \mathrm{~mm} / \mathrm{min}$.

\subsection{Failure Time}

Figure 3 represents the failure time (the time from the start of laser irradiation to the failure/fracture of the specimen) for both Al-6061 and Al-7075 as a function of laser power density for various preloaded speeds. For Al-6061 type specimens, with the increase of laser power density, failure time decreases. However, the decreasing trend is irregular for varying preloaded speeds. For the lowest laser power density of $1.1 \mathrm{~kW} / \mathrm{cm}^{2}$, with the increase of loading speed, there is a remarkable reduction in failure time especially for the maximum loading speed of $4 \mathrm{~mm} / \mathrm{min}$. However, for this power density $\left(1.1 \mathrm{~kW} / \mathrm{cm}^{2}\right)$, the specimens took a comparatively long time for complete failure. The failure time depends both on failure temperature, as well as on the temperature rise rate. The failure temperature belongs to preloading speed, while the temperature rise rate depends on laser power density. By the increase of laser power density to $1.6 \mathrm{~kW} / \mathrm{cm}^{2}$, the failure time drops to almost half or even less values under the same preload speeds, except for $1 \mathrm{~mm} / \mathrm{min}$. A further increase in laser power density to higher values causes more reduction in the failure time for the fixed loading speeds. By comparing different curves belonging to different loading speeds, it is found that there is a random effect of loading speeds on Al-6061 failure time. This non-uniformity is due to different thermo-mechanical responses to varying experimental conditions. There is a non-uniform distribution of local temperature and local residual stress during the irradiation process under different conditions. This non-uniformity (depending on the temperature rise rate) gives rise to a difference in the variation trend of thermophysical and mechanical properties, like thermal conductivity, the thermal expansion coefficient, yield strength, etc. The sufficiently high temperature rise rate may result in very high local temperature and local residual stress. The former may induce local softening, and the latter may cause 
local damage, which may degrade the mechanical properties of specimens and cause the specimen failure, even at a low level of preloaded speed or stress [24].
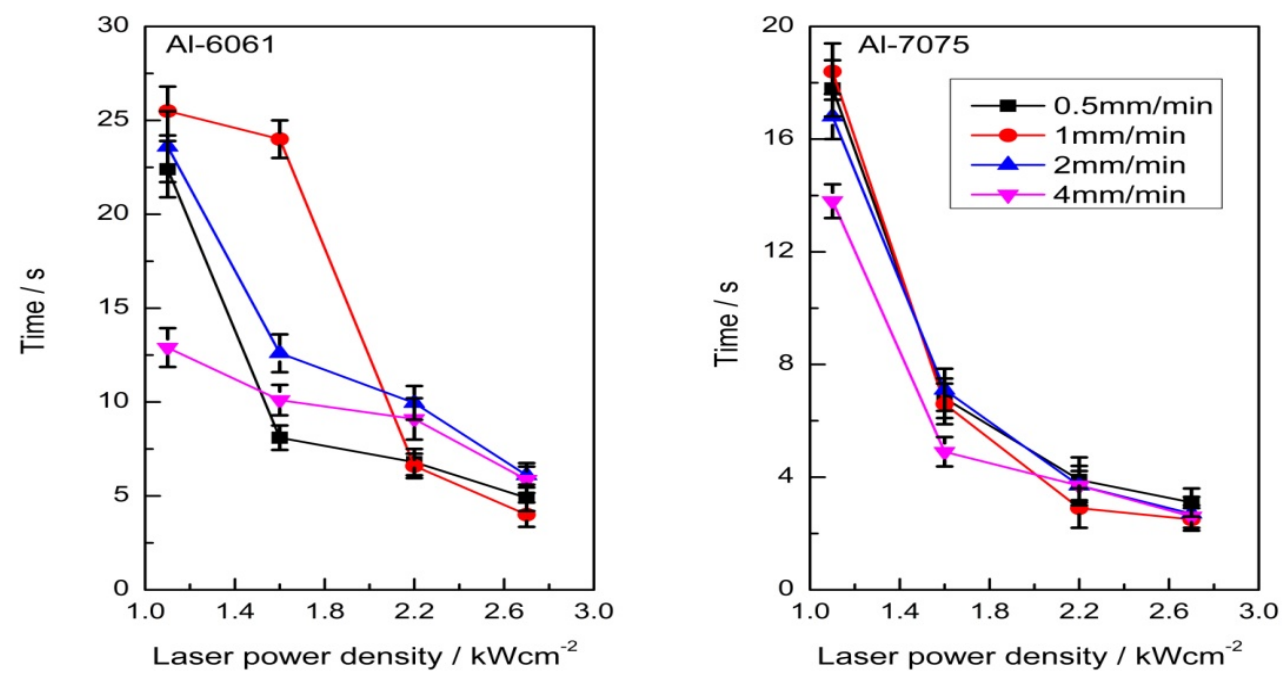

Figure 3. Failure time of Al-6061 and Al-7075 type specimens against laser power density, under different preloaded speeds.

For Al-7075 specimens, the failure time also decreased by increasing the laser power density. As compare to Al-6061, Al-7075 showed some regularity in the reduction in failure time for both laser power density and preloaded speeds. The failure time for the lowest power density $\left(1.1 \mathrm{~kW} / \mathrm{cm}^{2}\right)$ is largest for the $1 \mathrm{~mm} / \mathrm{min}$ case and relatively has smaller values for higher power densities. In addition, when the laser power density increases from 1.1 to $2.7 \mathrm{~kW} / \mathrm{cm}^{2}$, the failure time decreased by $14.7 \mathrm{~s}$, $15.9 \mathrm{~s}, 14.1 \mathrm{~s}$ and $11.2 \mathrm{~s}$, respectively, corresponding to preloaded speeds of $0.5,1,2$ and $4 \mathrm{~mm} / \mathrm{min}$. This indicates that for higher preloaded speeds, there is a smaller impact of laser power density on the failure time except in the case of $1 \mathrm{~mm} / \mathrm{min}$ preloaded speed.

According to Figure 3, the laser power density and average failure time relationship curve can be obtained as shown in Figure 4. An empirical formula is also obtained by fitting the data points, and then the failure time for different laser power densities can be estimated accordingly.
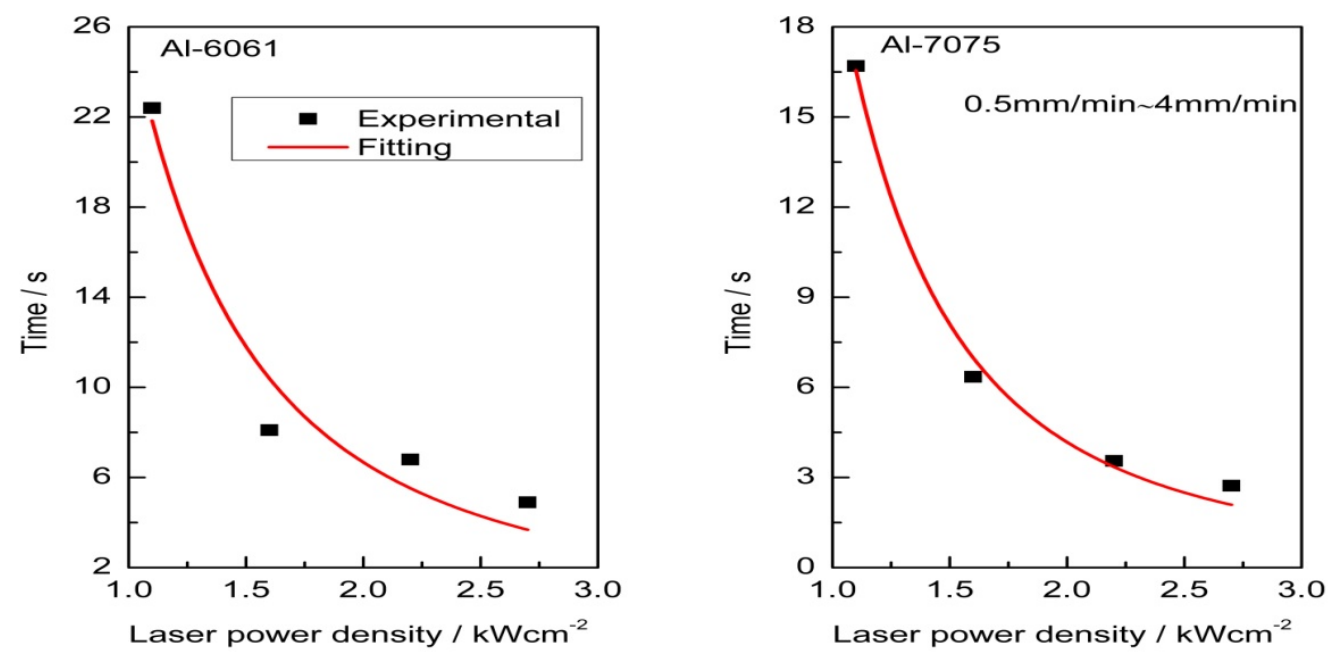

Figure 4. Fitting results of the failure time of Al-6061 and Al-7075 type specimens against laser power density. 
For Al-6061 specimens:

$$
t_{f}=26.4\left(P_{l}\right)^{-1.98} ;\left(1.1 \mathrm{kWcm}^{-2} \leq P_{l} \leq 2.7 \mathrm{kWcm}^{-2}\right),
$$

and for the Al-7075 type specimens:

$$
t_{f}=20.62\left(P_{l}\right)^{-2.31} ;\left(1.1 \mathrm{~kW} \mathrm{~cm}^{-2} \leq P_{l} \leq 2.7 \mathrm{~kW} \mathrm{~cm}^{-2}\right),
$$

Here, " $t_{f}$ " is the average failure time, whereas " $P_{l}$ " represents the laser power density.

There is a best fitting curve for Al-7075, but for Al-6061, a little deflection is found. The time in these curves corresponds to the average failure time belonging to different laser power densities.

\subsection{Rupture Morphology}

The previous Section 3.2 provides the strength degradation trend of tested specimens subjected to tensile preload and laser irradiation. However, no clear information on the failure mode and physical changes of the fractured specimens can be obtained from the presented results. Optical microscopy investigation was carried out to get more clear analysis of the failure mode and to explore the laser heating effects on the irradiated surfaces. Optical microscopy images for the lowest and highest employed laser power densities are presented below.

Figure 5a-d represents the surface rupture morphology for Al-6061 under the condition of the $1.1 \mathrm{~kW} / \mathrm{cm}^{2}$ laser power density with various preloaded speeds. According to the rupture morphology, the distinct necking in the irradiated area is observed for all of the preloaded speeds. The extent of necking seems to be near similar for all of the applied preloaded speeds. Moreover, on the rupture surface or on the near-fracture sections, no plastic changes, e.g., heat affected zone or any other deformation, appeared. At the macro-level, this rupture pattern indicates the brittle fracture mode.

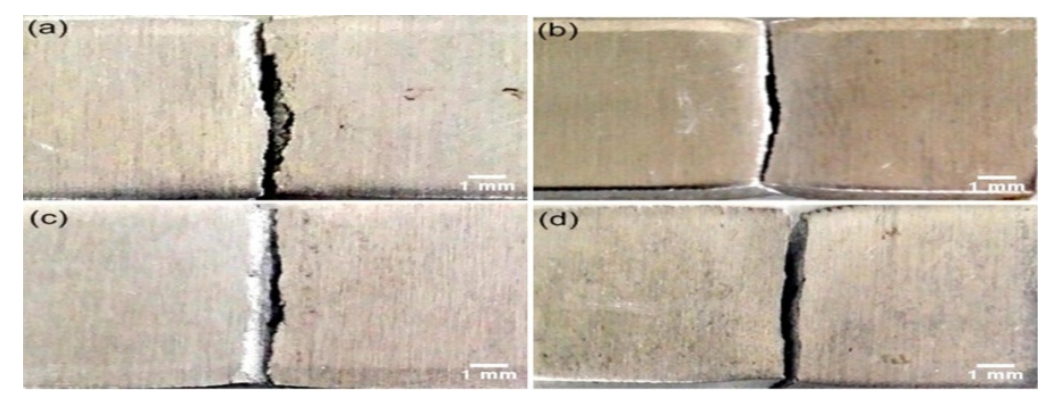

Figure 5. Rupture morphology of the Al-6061 specimens fractured under the conditions of $1.1 \mathrm{~kW} / \mathrm{cm}^{2}$ laser power density and various preloaded speeds of (a) $0.5 \mathrm{~mm} / \mathrm{min}$; (b) $1 \mathrm{~mm} / \mathrm{min}$; (c) $2 \mathrm{~mm} / \mathrm{min}$; (d) $4 \mathrm{~mm} / \mathrm{min}$.

For the laser power density of $2.7 \mathrm{~kW} / \mathrm{cm}^{2}$ in Figure $6 \mathrm{a}-\mathrm{d}$, generally, the heat-affected zone expanded in area by increasing the preloaded speed. Local combustion, melting, necking, thermal expansion and cracks can be observed on the irradiated surface. Moreover, for lower preloaded speeds (Figure 6a,b) due to thermal expansion, a small dimple is developed. For the $2 \mathrm{~mm} / \mathrm{min}$ preloaded speed (Figure 6c), comparatively less pronounced effects are found, and the specimen's burn through instead of thermal expansion is more obvious. This behavior may be explained as, for the combination of $2.7 \mathrm{~kW} / \mathrm{cm}^{2}$ laser power density and $2 \mathrm{~mm} / \mathrm{min}$ preloaded speed, the resulting temperature rise and heating rate did not allow the heat accumulation and localized effects. Meanwhile, it boosted the thermal activation, dynamic softening and failure process. 


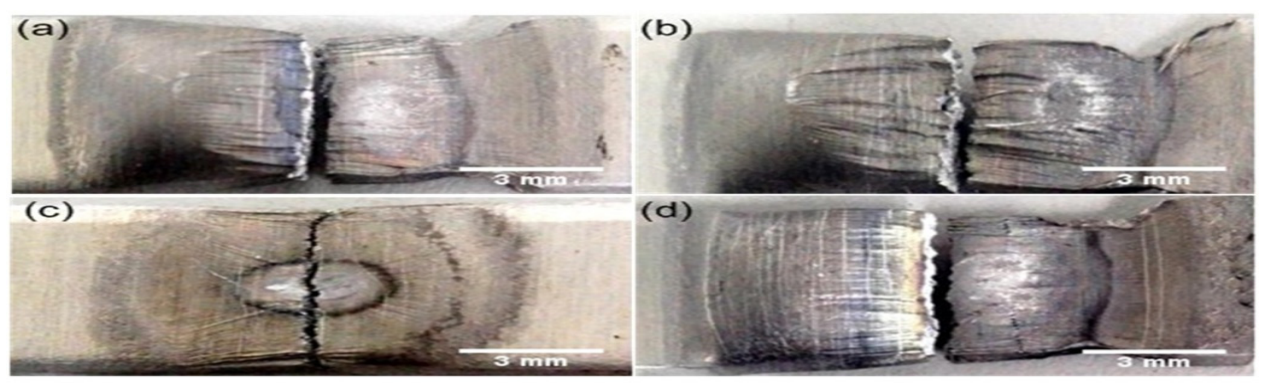

Figure 6. Rupture morphology of the Al-6061 specimens fractured under the conditions of $2.7 \mathrm{~kW} / \mathrm{cm}^{2}$ laser power density and various preloaded speeds of (a) $0.5 \mathrm{~mm} / \mathrm{min}$, (b) $1 \mathrm{~mm} / \mathrm{min}$, (c) $2 \mathrm{~mm} / \mathrm{min}$ and (d) $4 \mathrm{~mm} / \mathrm{min}$.

Figure 7a-d represents the surface rupture morphology for Al-7075 under the condition of $1.1 \mathrm{~kW} / \mathrm{cm}^{2}$ laser power density with various preloaded speeds. For $0.5 \mathrm{~mm} / \mathrm{min}$, the rupture pattern is in round or necked shape without any distinct surface deformation, except necking. Moreover, near the fracture sections, grains can be seen on the specimen's surface.
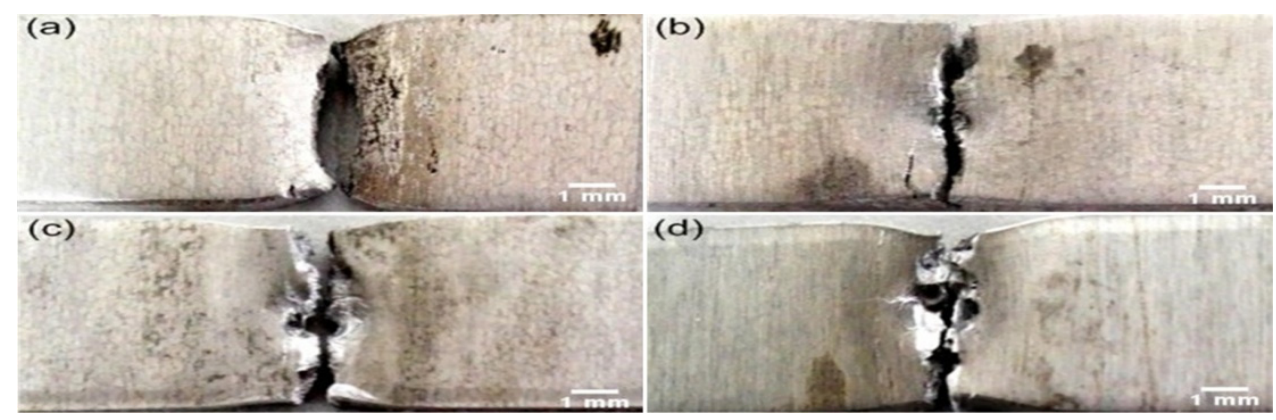

Figure 7. Rupture morphology of the Al-7075 specimens fractured under the conditions of $1.1 \mathrm{~kW} / \mathrm{cm}^{2}$ laser power density and various preloaded speeds of (a) $0.5 \mathrm{~mm} / \mathrm{Min}$; (b) $1 \mathrm{~mm} / \mathrm{Min}$; (c) $2 \mathrm{~mm} / \mathrm{Min}$; (d) $4 \mathrm{~mm} / \mathrm{Min}$.

For higher preloaded speeds, the common feature is hole formation before complete rupture. The hole formation is attributed to ablation of the melted part, which increased remarkably for higher preloaded speeds. In addition, with the increase of preloaded speeds, on the near fracture sections, grains reduced in size, become diffusive and finally completely vanished for the $4 \mathrm{~mm} / \mathrm{min}$ preloaded speed.

For the laser power density of $2.7 \mathrm{~kW} / \mathrm{cm}^{2}$ in Figure $8 \mathrm{a}-\mathrm{d}$, generally, the heat-affected zone expanded in depth and length by increasing the preloaded speed. Local damaging and combustion, melting, necking, ablation and cracks may be seen on the irradiated surfaces. Moreover, near the irradiated area/fractured surface, the development of grains can be found, which becomes more distinct with the increase of preloaded speeds up to $2 \mathrm{~mm} / \mathrm{min}$. For the highest preloaded speed, the presented results of Figure $8 \mathrm{~d}$ showed the relatively high plastic surface deformation instead of distinct grains. The increasing preloading speed makes the local effects expand and severe. At higher preloaded speeds, a greater degree of melting and ablation phenomenon can be seen due to relatively higher temperatures and higher heating rates. From this morphology figure, it may be concluded that higher preloaded speeds boosted the failure mechanism along with expanded plastic deformations. 


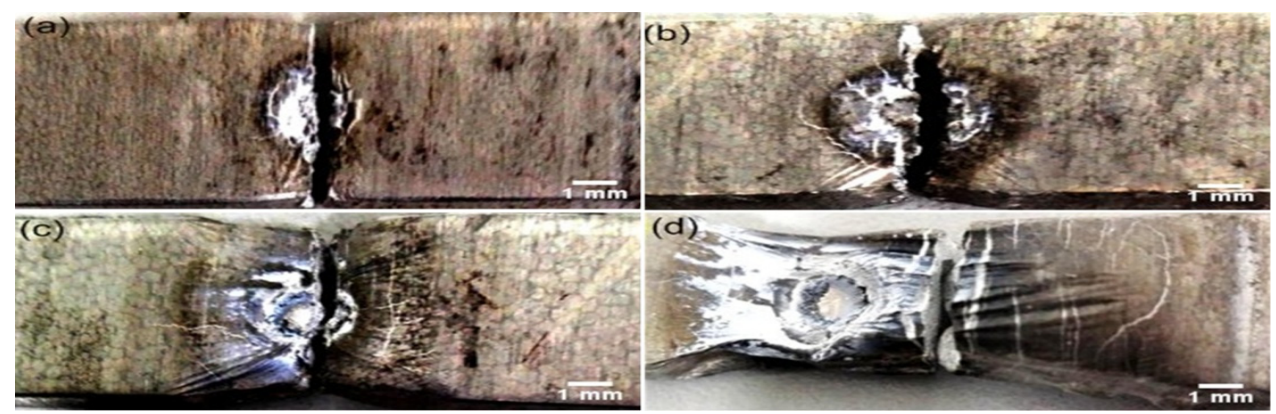

Figure 8. Rupture morphology of the Al-7075 specimens fractured under the conditions of $2.7 \mathrm{~kW} / \mathrm{cm}^{2}$ laser power density and various preloaded speeds of (a) $0.5 \mathrm{~mm} / \mathrm{min}$; (b) $1 \mathrm{~mm} / \mathrm{min}$; (c) $2 \mathrm{~mm} / \mathrm{min}$; (d) $4 \mathrm{~mm} / \mathrm{min}$.

\section{Further Investigations}

Although we were tried to understand the influence of each individual parameter (preload speed and laser power density) on the failure response of aluminum alloys, the raised research question could not be answered completely. This is probably due to the complexity of the combined effect of laser heating and preload. Perhaps relatively more systematic and in-depth understanding of the combined effects requires additional information. For instance, the knowledge of strain distribution (temporal and spatial) and temperature evolution during laser heating may help for deeper investigation and better understanding of the combined effects.

\section{Conclusions}

The present study experimentally examined the failure behavior of Al-6061 and Al-7075 alloys exposed to combined tensile loading and laser irradiations. Tensile loading was provided by a universal tensile testing machine, and a 1080-nm wavelength CW fiber laser was used for laser irradiations. From the experimental results, the specimen's failure time is found to reduce by increasing either the laser power density or preloaded speed. The effects of increased preloaded speeds on the variation of Al-6061 failure time are significant, but random. For Al-7075, under higher preloaded speeds, there is smaller impact of laser power density on the failure time. However, from the fitting results, it may be noticed that the Al-7075 average failure time variation with laser power density tends to follow some relationship. The non-uniformity in the decrease of failure time is due to different thermo-mechanical responses to varying experimental conditions. The non-uniform and inconsistent changes (depending on the temperature rise rate) of the local temperature and local stress during the irradiation process under different test conditions give rise to differences in the variation trend of thermophysical and mechanical properties, like thermal conductivity, the thermal expansion coefficient, yield strength, etc. From the rupture morphology, it is found that, by the increase of laser power density or preloaded speed, the failure mode changed from brittle to ductile. At higher power densities, local damaging and combustion, melting, necking, ablation and cracks may be seen on the irradiated surfaces. Moreover, the increasing preloading speed makes the local effects expand.

Acknowledgments: This work is supported by the National Natural Science Foundation of China (6160-5079) and the Fundamental Research Funds for the Central Universities (30916-014-112-020).

Author Contributions: Zhonghua Shen and Mohsan Jelani conceived of and designed the experiments. Mohsan Jelani and Zewen Li performed the experiments and analyzed the data. Maryam Sardar helped in analyzing the results. Mohsan Jelani wrote the paper.

Conflicts of Interest: The authors declare no conflict of interest. 


\section{References}

1. Nichols, J.W.; Mall, S. The fracture behavior of thin $6061 \mathrm{t}-6$ aluminum at rapid heating rates. Eng. Fract. Mech. 1989, 32, 787-794. [CrossRef]

2. Griffis, C.; Chang, C.; Stonesifer, F. Thermo-mechanical response of tension panels under intense rapid heating. Theor. Appl. Fract. Mech. 1985, 3, 41-48. [CrossRef]

3. Semb, E. Behavior of Aluminum at Elevated Strain Rates and Temperatures. Master's thesis, Institutt for konstruksjonsteknikk, Trondheim, Norway, 2013.

4. Legner, H.; Popper, L.; Laughlin, W.; Pugh, E. Analysis of rp laser experiments on tensile-loaded materials. In Proceedings of the 24th Plasma Dynamics and Lasers Conference, Orlando, FL, USA, 6-9 July 1993; AIAA: Reston, VA, USA, 1993; p. 3203.

5. El-Magd, E.; Abouridouane, M. Characterization, modelling and simulation of deformation and fracture behaviour of the light-weight wrought alloys under high strain rate loading. Int. J. Impact Eng. 2006, 32, 741-758. [CrossRef]

6. Lee, W.S.; Sue, W.C.; Lin, C.F.; Wu, C.J. The strain rate and temperature dependence of the dynamic impact properties of 7075 aluminum alloy. J. Mat. Proc. Technol. 2000, 100, 116-122. [CrossRef]

7. Chen, J.; Young, B. Stress-strain curves for stainless steel at elevated temperatures. Eng. Struct. 2006, 28, 229-239. [CrossRef]

8. Maljaars, J.; Soetens, F.; Katgerman, L. Constitutive model for aluminum alloys exposed to fire conditions. Metallur. Mat. Trans. A 2008, 39, 778-789. [CrossRef]

9. Seidt, J.; Gilat, A. Plastic deformation of 2024-t351 aluminum plate over a wide range of loading conditions. Int. J. Sol. Struct. 2013, 50, 1781-1790. [CrossRef]

10. Florando, J.; Margraf, J.; Reus, J.; Anderson, A.; McCallen, R.; LeBlanc, M.; Stanley, J.; Rubenchik, A.; Wu, S.; Lowdermilk, W. Modeling the effect of laser heating on the strength and failure of 7075-t6 aluminum. Mat. Sci. Eng. A 2015, 640, 402-407. [CrossRef]

11. Medford, J.E.; Gray, P.M. The response of structural materials to combined laser and mechanical loading. In Proceedings of the 15th Thermophysics Conference, Snowmass, CO, USA, 14-16 July 1980; AIAA: Reston, VA, USA; p. 1550.

12. Long, L.C.; Wang, T.T.; Liu, L.T. Tensile and compression test of carbon/epoxy composite laminate under combined action of laser irradiation and load. Mat. Res. Innov. 2015, 19, 171-176. [CrossRef]

13. Zhu, Y.; Ye, X.; Lin, X.; Wei, C.; Wang, L.; Cheng, D. Experimental investigation on the damage effect of steel structure by continuous laser under preloaded invariable stretching stress. In Proceedings of the 2nd International Symposium on Laser Interaction with Matter, Xi'an, China, 9 September 2012; SPIE: Bellingham, WA, USA, 2013; p. 8796.

14. Christy, T.; Murugan, N.; Kumar, S. A comparative study on the microstructures and mechanical properties of Al 6061 alloy and the MMCAl 6061/tib2/12p. J. Miner. Mat. Charact. Eng. 2010, 9, 57.

15. Dursun, T.; Soutis, C. Recent developments in advanced aircraft aluminium alloys. Mat. Des. 2014, 56, 862-871. [CrossRef]

16. Irizalp, S.G.; Saklakoglu, N.; Akman, E.; Demir, A. Pulsed Nd: Yag laser shock processing effects on mechanical properties of 6061-t6 alloy. Opt. Laser. Technol. 2014, 56, 273-277. [CrossRef]

17. Mocko, W.; Rodriguez-Martinez, J.A.; Kowalewski, Z.L.; Rusinek, A. Compressive viscoplastic response of 6082-t6 and 7075-t6 aluminium alloys under wide range of strain rate at room temperature: Experiments and modelling. Strain 2012, 48, 498-509. [CrossRef]

18. Irizalp, S.G.; Saklakoglu, N. High strength and high ductility behavior of 6061-t6 alloy after laser shock processing. Opt. Laser Eng. 2016, 77, 183-190. [CrossRef]

19. Lee, H.T.; Shaue, G.H. The thermomechanical behavior for aluminum alloy under uniaxial tensile loading. Mat. Sci. Eng. A 1999, 268, 154-164. [CrossRef]

20. ASM, H. Properties and selection: Nonferrous alloys and special-purpose materials. ASM Int. 1990, 2, 889-896.

21. Boyer; Gall, T.L. Handbook, Asm Metals; American Society for Metals: Materials Park, OH, USA, 1985.

22. Bowyer, J.; Luketa, A.; Gill, W.; Donaldson, B. Aluminum behavior during fire heating: Focus on deformation. Fire Saf. Sci. 2011, 10, 1151-1164. [CrossRef] 
23. Sheng, Z.M.; Weng, S.M.; Yu, L.L.; Wang, W.M.; Cui, Y.Q.; Chen, M.; Zhang, J. Absorption of ultrashort intense lasers in laser-solid interactions. Chin. Phys. B 2015, 24, 015201. [CrossRef]

24. Peng, X.H.; Fan, J.; Yang, Y.; Chen, Y.; Yin, Y. Investigations to the effect of heating-rate on the mechanical properties of aluminum alloy ly12. Int. J. Sol. Struct. 2003, 40, 7385-7397. [CrossRef]

25. Summers, P.T.; Chen, Y.; Rippe, C.M.; Allen, B.; Mouritz, A.P.; Case, S.W.; Lattimer, B.Y. Overview of aluminum alloy mechanical properties during and after fires. Fire Sci. Rev. 2015, 4, 1-36. [CrossRef]

26. Jones, $\mathrm{H}$; $\mathrm{Wu}, \mathrm{K}$. Tensile instability and deformation behavior of rapidly heatedmetals in a constant-load environment. Inter. J. Thermophys. 1990, 11, 675-691. [CrossRef]

(c) 2017 by the authors. Licensee MDPI, Basel, Switzerland. This article is an open access article distributed under the terms and conditions of the Creative Commons Attribution (CC BY) license (http:/ / creativecommons.org/licenses/by/4.0/). 